\title{
¡Por la democracia y libertad de Guatemala! Exiliados del ubiquismo en la frontera sur de México (1934-1938)
}

\section{For the Democracy and Freedom of Guatemala! Exiles During the Ubico Administration on the Southern Border of Mexico (1934-1938)}

\author{
Luis Gerardo Monterrosa Cubías* \\ (D) https://orcid.org/0000-0002-5846-7418 \\ Centro de Investigaciones Multidisciplinarias sobre Chiapas y la Frontera Sur \\ Universidad Nacional Autónoma de México, México \\ gerardomonterrosa20@gmail.com
}

Resumen: En el presente artículo se examina la actividad de dos exiliados del régimen presidido por Jorge Ubico (1931-1944) en México durante el cardenismo y la reacción de ambos gobiernos para dilucidar por qué, pese a la intención del gobierno mexicano de mantenerse al margen de los asuntos políticos guatemaltecos, Miguel García Granados y Clemente Marroquín Rojas rondaron la frontera sur de México y encendieron las alarmas del oficialismo. A través de una indagación en los archivos de Guatemala y México, incluyendo Chiapas, el estudio del exilio guatemalteco adquiere matices renovados, in-

* Pertenece al Programa de Becas Posdoctorales de la unam y es becario del Centro de Investigaciones Multidisciplinarias sobre Chiapas y la Frontera Sur, asesorado por el doctor Miguel Lisbona Guillén.

cómo citar: Monterrosa Cubías, L. G. (2020). ¡Por la democracia y libertad de Guatemala! Exiliados del ubiquismo en la frontera sur de México (1934-1938). Secuencia (107), e1736. DoI: https://doi.org/10.18234/ secuencia.v0i107.1736 
sertándolo en la frontera sur y mostrando las redes de apoyo que los desterrados forjaron con los disidentes del cardenismo.

Palabras clave: disidencia política; exilio; continuismo; relaciones diplomáticas; autoritarismo.

Abstract: This article examines the activity of two exiles from the regime led by Jorge Ubico (1931-1944) in Mexico during the Cardenas administration and the reaction of both governments to determine why, despite the intentions of the Mexican government to stay out of Guatemalan political affairs, Miguel García Granados and Clemente Marroquín Rojas hovered around the southern border of Mexico, setting off alarms for the ruling party. Through an investigation into the archives of Guatemala and Mexico, including Chiapas, the study of the Guatemalan exile acquires fresh nuances, inserting it into the southern border and showing the support networks exiles formed with cardenism dissidents.

Keywords: political dissent; exile; continuity; diplomatic relations; authoritarianism.

Recibido: 03 de abril de 2019 Aceptado: 29 de julio de 2019

Publicado: 17 de marzo de 2020

\section{INTRODUCCIÓN}

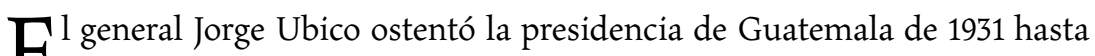
1944. "Hombre sagaz, amante de la austeridad y el orden -como apuntó un funcionario mexicano a principios de los años cuarenta-, funda su poder en un ejército disciplinado y en la más enérgica represión cuando la cree necesaria. Un partido oficial, el Liberal Progresista, aparece como la base popular de su gestión." El general Ubico conoció a seis gobernantes mexica-

${ }^{1}$ Memorándum para la embajada de México en Guatemala. S. f., exp. III-1963-12. Archivo Histórico Genaro Estrada de la Secretaría de Relaciones Exteriores de México (en adelante AHGE-SRE), México. 
nos durante sus lustros al frente del ejecutivo guatemalteco. Instalado en el palacio nacional -edificado en su administración-, observó el desarrollo del maximato bajo la protección de Plutarco Elías Calles, la llegada al poder de Lázaro Cárdenas y su consolidación luego de la expulsión del jefe máximo del Partido Nacional Revolucionario (PNR), y una buena parte del mandato de Manuel Ávila Camacho (1940-1946). Anticomunista militante y apoyado por Washington, Ubico dirigió siempre una mirada suspicaz hacia México al estimar que el régimen posrevolucionario había hecho de este país un semillero del comunismo. Empero, esta apreciación no le impidió emprender acciones conjuntas con sus vecinos $y$, sobre todo, solicitarles que apaciguaran la beligerancia de los exiliados guatemaltecos. ${ }^{2}$

El objetivo del presente artículo consiste, precisamente, en examinar la actividad de dos exiliados del ubiquismo en México durante el cardenismo y la reacción de ambos gobiernos para dilucidar por qué, pese al prurito del régimen mexicano de no intervenir en los asuntos domésticos de Guatemala, Miguel García Granados y Clemente Marroquín Rojas merodearon la frontera sur y encendieron las alarmas de los círculos oficiales. Ciertamente, este planteamiento necesita atender tres aristas postuladas por los especialistas del exilio en América Latina: primero, la exclusión del dominio público realizada por un gobierno que utilizó el destierro como mecanismo regulador del sistema político; segundo, el objetivo de los exiliados, sus movimientos y actividades en el extranjero y, tercero, los intereses del gobierno anfitrión, su política de asilo, los canales de apoyo y las limitaciones impuestas a los exilia$\operatorname{dos}^{3}$ (Sznajder y Roniger, 2013).

Por consiguiente, abordar el objeto de estudio desde este esquema triádico instituye como protagonista a un régimen guatemalteco caracterizado

${ }^{2}$ La tarea conjunta más sobresaliente de este periodo fue la delimitación fronteriza. En efecto, al deteriorarse las relaciones bilaterales después del ascenso de Jorge Ubico, "la frontera fue asumiendo cada vez con mayor claridad su carácter estricto de acotación divisoria y, en consecuencia, se tornó en un surtidor de conflictos y desacuerdos que sólo con el transcurso de muchos años guatemaltecos y mexicanos aprenderían a resolver" (Castillo, Toussaint y Vázquez, 2006, pp. 206-207).

${ }^{3}$ En aras de la rigurosidad conceptual de este escrito es necesario establecer qué se entenderá por exilio. Al respecto, tomo la definición de Mario Sznajder y Luis Roniger (2013, p. 31), para quienes es "un mecanismo de exclusión institucional, no el único, mediante el cual alguien involucrado en la política y en la vida pública [...] es forzado a abandonar su país de origen, imposibilitado de regresar hasta que haya una modificación en las circunstancias políticas". Además, sigo a estos autores en el uso indistinto del concepto de destierro y asilo político. 
por su política de ausencias en cuanto a la expulsión de cualquier signo opositor de su territorio; al gobierno de Lázaro Cárdenas que le dio continuidad a la tradición del asilo político en México (Serrano, 2002) y, claro está, a los cuadros que llegaron a la nación vecina con un propósito en mente: deponer al ubiquismo. Por otra parte, la temática examinada se inscribe en terrenos que han sido abordados en trabajos precedentes. Me refiero al exilio latinoamericano en México, las relaciones diplomáticas de este gobierno con Centroamérica y las dimensiones de la frontera compartida por Guatemala y México. La copiosa información disponible orienta la investigación, la enriquece, pero también sugiere citar los trabajos publicados acerca del tema. A continuación, elaboraré un breve estado de la cuestión que permita indicar los aportes de esta investigación.

\section{EL ESTADO DE LA CUESTIÓN}

El tema del exilio en México ha sido abordado en distintos trabajos. Se cuenta con mucha bibliografía sobre los casos español, cubano y sudamericano. Desde los republicanos que huyeron del franquismo (Lida, 1997), pasando por los que arribaron de la isla acosados por los regímenes de Batista y luego el revolucionario (Serrano, 2002), hasta los uruguayos, argentinos y chilenos que evadieron el cerco del Plan Cóndor (Groppo y Flier, 2001). México fue la morada temporal y en ciertos casos permanente de los que vivieron, según palabras de Victor Hugo, un largo sueño con el hogar. "El apacible refugio de los perseguidos y el escenario magnífico de la discusión libre de todas las ideas", según la expresión de Patricio Brannon, abogado salvadoreño enviado a México como embajador en 1944, después de permanecer en las cárceles del gobierno encabezado por Maximiliano Hernández Martínez (1931-1944). ${ }^{4}$

Pero la atención ha sido colocada en otros exilios menos emblemáticos, como el judío, alemán, dominicano y centroamericano. Son de especial importancia los trabajos acerca de estos últimos para establecer los aportes del presente artículo. Laura Moreno (2012 y 2015) ha estudiado, por ejemplo, el exilio nicaragüense y costarricense de los años treinta y cuarenta. Otra contribución es la obra de Guadalupe Rodríguez de Ita (2003), quien analizó la

${ }^{4}$ Discurso del embajador salvadoreño en México durante el acto de entrega de cartas credenciales. S. f., exp. 24-1-73. AHgE-SRE, México. 
política mexicana del asilo diplomático a la luz del caso guatemalteco: 19441954. Además, Luis Balcárcel (2010) construyó una extensa semblanza del exilio de esta nación desde el régimen de Estrada Cabrera (1898-1920) hasta los jefes de las agrupaciones guerrilleras arribados a partir de los años sesenta. Estos trabajos constituyen aportes destacados, examinan una de las opciones que un opositor de Estrada Cabrera, Alfonso Orantes, estableció para quien osara interpelar los designios del señor presidente: encierro, destierro y entierro. Pero también es cierto que faltan espacios por iluminar, entre estos las acciones de los exiliados guatemaltecos durante los años treinta en México.

Miguel García Granados y Clemente Marroquín Rojas integraron un grupo de exiliados proactivos, es decir, que se mantuvieron en pie de lucha desde el extranjero. Una vez en México se organizaron con sus compatriotas, denunciaron al ubiquismo y pidieron apoyo para deponerlo. Su activismo puso a prueba las complicadas relaciones diplomáticas entre Guatemala y México; una vecindad sobre la cual se han elaborado sugerentes trabajos. Luis Zorrilla (1984) y Beatriz Veliz (2008) explicaron un elemento común: la suspicacia de Ubico ante el gobierno mexicano y el objetivo de este último por sortear la confrontación. "Puertas abiertas hacia ninguna parte" fue el título de un parágrafo que Manuel Castillo, Mónica Toussaint y Mario Vázquez escribieron en su estudio del periodo en cuestión (Castillo, Toussaint y Vázquez, 2011). Su análisis exhibe el distanciamiento adoptado por el gobierno mexicano hacia su vecindad sureña y la indiferencia ante las tropelías de un régimen que difería totalmente de los principios de la revolución mexicana. ${ }^{5}$

Ahora bien, si imperó un respeto mutuo plagado de recelo e indiferencia en la relación de estos vecinos, ¿por qué la actividad de los exiliados guatemaltecos incrementó su comunicación y suspendió por un momento esta distancia? La respuesta apunta al entramado de la frontera sur de México estudiado por Jan de Vos (2002) y Castillo, Toussaint y Vázquez (2006), entre otros; quienes reconstruyeron la genealogía de dicho espacio y sus dimensio-

${ }^{5}$ Durante el cardenismo las diferencias entre los regímenes eran evidentes. El gobierno mexicano buscó legitimarse con la participación activa de los trabajadores y campesinos. El ubiquismo confió en las medidas coercitivas y sus pactos con los caciques regionales. Esta situación fue descrita por un funcionario mexicano, quien escribió: "no existe en Guatemala ninguna organización de defensa económica del trabajo (ni institución jurídica que la proteja) y cualquier actividad en este sentido, aun cuando no exceda la simple manifestación de ideas, es vista y catalogada como comunismo". Memorándum para la embajada de México en Guatemala. S. f., exp. III-1963-12. AHge-SRE, México. 
nes. Y retomaré la dimensión de la frontera como lugar de disidencia; una región donde puede suscitarse un choque entre los actores locales y las directrices del centro político, un espacio en el cual su porosidad y la precariedad de los controles oficiales permiten actividades insurgentes encubiertas. En el presente artículo incursiono en una temática poco estudiada en la historiografía mexicana y centroamericana. Abordo el exilio guatemalteco en México desde el interés de los gobiernos y de los desterrados, pero profundizo en este último a través de una revisión de la política chiapaneca y de los contactos que los exiliados urdieron en el Soconusco. En otras palabras, el aporte de esta investigación consiste en trasladar el estudio del exilio guatemalteco de la capital mexicana hacia las fronteras. Ese lugar problemático para ambos gobiernos, pero tan preciado por sus disidentes.

Abro el telón con la represión del ubiquismo, en 1934, que generó su política de exclusión y de ausencias. Prosigo con un boceto biográfico de los exiliados. Luego, examino los contactos de los desterrados y sus inconvenientes, la política exterior del cardenismo hacia su vecino sureño $y$, finalmente, hago un estudio del escenario político chiapaneco de los años treinta y los colaboradores locales que tuvieron los guatemaltecos.

\section{EL ATENTADO ABORTADO DE 1934}

Intensas jornadas de trabajo tuvieron los funcionarios de la Auditoría de Guerra en septiembre de 1934, ya que durante los primeros días del mes se desarticuló un atentado contra la integridad física de Jorge Ubico. Los cuartos donde se efectuaban los interrogatorios se mostraban abarrotados. Más de una quincena de supuestos complotados resistían el bombardeo de preguntas de los detectives. Entre los detenidos estaba Jacobo Sánchez, de 26 años de edad, oriundo de Quetzaltenango. En el parte oficial fue descrito como soldado afiliado de la Escuela Politécnica, sin grado militar o enfermedad mental, pero con antecedentes penales por asuntos políticos. El acta donde apuntaron sus declaraciones nos permite conocer el proyecto conspirativo. ${ }^{6}$

${ }^{6}$ Acta del interrogatorio efectuado a Jacobo Sánchez. 27 de septiembre de 1934. Fondo de Relaciones Exteriores, B, leg. 6722. Archivo General de Centro América (en adelante AGCA), Guatemala. 
Sánchez Calderón fue instado a integrar la confabulación en junio de 1934. En esta fecha, un coronel del ejército le expresó la urgencia de segar la vida del presidente, quien contemplaba la reelección. Sánchez caviló por un tiempo su respuesta y terminó aceptando la invitación. Días más tarde, el militar le presentó a dos coludidos más con los cuales sortearon la férrea vigilancia del régimen para esconder algunas bombas en las instalaciones de una escuela. En esta diligencia Sánchez entabló contacto con Carlos Pacheco Marroquín y Efraín Fuentes, civiles que después la policía señaló como autores intelectuales del atentado abortado. Según el imputado, estos querían aprovechar el desplazamiento de Ubico por la capital para concretar sus planes, lanzando ataques simultáneos en diversos cuarteles. El puente cercano a la penitenciaría, el parque La Concordia y la avenida Reforma fueron considerados, optando finalmente por el primer sitio.

Los vehículos para transportar los explosivos estaban dispuestos y el plazo para activarlos establecido: la segunda quincena de septiembre. Sánchez definió su suerte al afirmar que entregó "cuatro candelas de dinamita y que las tenía en su poder desde hacía siete años más o menos". ${ }^{7}$ El sindicado continuó colaborando con las autoridades, pero al ser trasladado al cantón Barillas, donde afirmó resguardar más explosivos, intentó huir en la oscuridad del amanecer "por cercos y sitios por lo que fue ultimado al intentar su captura", como reza el parte oficial. ${ }^{8}$

Al epílogo trágico de Sánchez le siguió el de muchos implicados en la conspiración, quienes fueron condenados a muerte por el delito de rebelión frustrada y sedición consumada. El pelotón de fusilamiento acató las órdenes del tribunal de guerra, y la penitenciaría central, descrita con minuciosidad lúgubre en las memorias de un prisionero -Efraín de los Ríos (1969)-, se transformó en el paradero de aquellos que tuvieron una participación mínima en el complot.

El temor y la zozobra cundieron entre los habitantes de la capital durante varias semanas: testigos de los cateos y capturas efectuados por la

\footnotetext{
${ }^{7}$ Acta del interrogatorio efectuado a Jacobo Sánchez. 27 de septiembre de 1934. Fondo de Relaciones Exteriores, B, leg. 6722. AGCA, Guatemala.

8 "13 sentenciados a muerte; complot contra Ubico", El Universal, 20 de septiembre de 1934, pp. 1 y 4 . Un día después fue publicada una nota en el periódico oficial del ubiquismo donde expusieron "la ingratitud y traición" de Jacobo Sánchez, a quien el régimen había exonerado de las cuotas de estudio en la carrera de jurisprudencia. "De la ingratitud a la traición", El Liberal Progresista, 21 de septiembre de 1934, p. 1.
} 
policía. El ubiquismo desplegó todas sus armas como lo hizo en 1932, cuando expresaron haber neutralizado una conspiración comunista. ${ }^{9} \mathrm{Si}$ en aquella fecha la represión sirvió para entronizar a Ubico como el paladín del anticomunismo, dos años más tarde el frustrado atentado fue utilizado para allanar el camino de la reelección. De esta forma, los enemigos del régimen, reales o potenciales, sucumbieron ante una emboscada relatada con detalle por el embajador mexicano en su informe.

Gustavo Serrano comenzó informando sobre la confabulación descubierta al secretario de Relaciones Exteriores, José Manuel Puig, y culminó solicitando instrucciones ante una situación comprometedora. Se rumoraba que uno de los implicados, Carlos Pacheco Marroquín, se hallaba asilado en la embajada mexicana; sospecha ante la cual agentes policiales fueron ubicados frente a este recinto. Finalmente, las dudas se diluyeron cuando la policía halló a Pacheco oculto en una residencia del centro capitalino. El imputado, al percatarse de la presencia de los agentes -citando una vez más la versión oficial-, opuso resistencia y murió en la balacera.

A estas alturas dos de los supuestos coludidos habían fallecido a manos de las autoridades antes de una sentencia. ¿Mera coincidencia o ejecuciones extrajudiciales? Difícil saberlo, pero lo cierto fue que el régimen continuó su persecución. "Parece que el proyectado plan terrorista ha aterrorizado al gobierno -adujó el embajador mexicano-y este a su vez al pueblo de Guatemala, pues la zozobra y la intranquilidad y el dolor se reflejan en todas las capas sociales." ${ }^{10}$ Serrano era consciente que la situación competía exclusivamente al ubiquismo, pero le fue imposible permanecer indiferente ante el drama humano que se vivía y a las peticiones de asilo que recibía. El diplomático debía tomar decisiones y precisaba instrucciones concisas de sus superiores.

En medio de la persecución y los consejos de guerra, preámbulo de los fusilamientos que el régimen se esmeró en publicitar, el cuerpo diplomático mexicano encarnó una posible tabla de salvación para los condenados al paredón. ${ }^{11}$ De hecho, el embajador mexicano, ante la solicitud de algunos fami-

9 Dos trabajos resultan sugerentes para observar la forma en que el ubiquismo aprovechó las rebeliones acaecidas en El Salvador en 1932 y justificó la represión. Taracena (1989) y Gleijeses (1989).

${ }^{10}$ Informe del embajador mexicano en Guatemala al secretario de Relaciones Exteriores de México. S. f., exp. 34-6-13. F. 37. Ahge-SRe, México.

${ }^{11}$ El castigo ejemplarizante a los supuestos coludidos fue anunciado y relatado en el periódico oficial: "En el patio de la Penitenciaría se formó el pelotón que tenía a su cargo el fu- 
liares de un sentenciado, intercedió ante el ministro de Relaciones Exteriores guatemalteco, Alfredo Skinner Klée, sin ningún resultado favorable. La impotencia y la frustración invadieron a Serrano, como se lo informó a su superior; pero el diplomático transitó por los parámetros establecidos en la Convención sobre Asilo Político de La Habana (1928) y Montevideo (1933). El funcionario no debía conceder este recurso a los condenados por un tribunal de guerra (Ímaz, 1995). Bajo este argumento, el recinto diplomático, a diferencia de lo acontecido tras la renuncia de Ubico en 1944, estuvo lejos de constituir un oasis una década antes. Sin embargo, su proceder fue aprobado y hasta aplaudido por el secretario de Relaciones Exteriores, quien, argumentando el temor de que surgieran eventos similares en México, escribió a su embajador:

Me doy perfecta cuenta de las especiales molestias y hasta aflicciones que pudo usted haber tenido en estos días y no dudo que su impulso generoso y humanitario habría sido el de ayudar en algo a los que fueron víctimas; pero estoy también absolutamente seguro de que nada se habría conseguido sino despertar con toda justificación las suspicacias de ese Gobierno, exactamente como no se conseguiría nada y se despertarían suspicacias en una acción semejante de cualquier representante extranjero ante actos que el Gobierno de México hubiera considerado ayer o considerará mañana indispensables para la represión de cualquier asonada. ${ }^{12}$

Por esta razón, José Manuel Puig recomendó ecuanimidad y absoluto respeto hacia el ubiquismo, pretendiendo, según su apreciación, "borrar completamente para el futuro las suspicacias por las acciones del pasado". Con esta postura el maximato se alejó de su proceder en Centroamérica de los años veinte, cuando Calles entregó pertrechos de guerra a Juan Bautista Sacasa en Nicaragua (Wünderich, 2009) y adoptó una política exterior que generó el mensaje de Sandino dirigido al presidente Portes Gil: "Yo no he venido a México con el fin de adaptarme a una cómoda y pasiva vida de político desterrado. Fracasada la misión que me trajo [procurarse armamento] vuelvo

silamiento; de sus respectivas bartolinas fueron extraídos los reos y conducidos al centro del patio donde se encontraba el auditor de guerra, fiscales militares y demás personas aludidas". "Pasados por las armas Aguilar Fuentes y los involucrados en el complot", El Liberal Progresista, 18 de septiembre de 1934, p. 1.

${ }_{12}$ Comunicación del secretario de Relaciones Exteriores de México al embajador mexicano en Guatemala. S. f., exp. 34-6-13. F. 80. AHGE-SRE, México. 
a ocupar mi posición al frente del ejército autonomista de mi país" (Ramírez, 2009). El gobierno mexicano, ocupado en amainar las tensiones a flor de piel de la familia revolucionaria y sofocar los combates con el clero de Veracruz, Tabasco y Jalisco, actuó ante la represión en Guatemala como esperaba que sus vecinos reaccionaran ante un eventual levantamiento de sus enemigos.

Mientras tanto, la mano de hierro del régimen vecino no encontró límite alguno, aunque las voces que pidieron clemencia aparecieron. Jorge García Granados, político y abogado, dirigió una carta al presidente. Un juicio comedido de la confabulación y el perdón hacia los condenados colorearon sus párrafos. En uno de estos escribió:

Por otra parte, a usted le faltan solamente poco más de dos años para terminar su periodo presidencial. Con un gobierno enérgico como el suyo y un sistema policíaco de vigilancia como el actual, todo complot está llamado a abortar. [...] Sea magnánimo, olvide los nuevos agravios y recuerde nada más los antiguos servicios. Un perdón humillará a los amigos que, desatendiendo los afectos, se volvieron contra usted; la muerte, en cambio, hará de ellos mártires eternamente llorados. ${ }^{13}$

Sin embargo, este razonamiento cayó en saco roto. La magnanimidad lució ausente del glosario del régimen. De hecho, el 13 de septiembre de 1934, publicaron un editorial donde justificaron la represión. En sus páginas adujeron que la sedición era admisible cuando se lidiaba con el andar oprobioso de los gobernantes "ineptos, descentrados, retrógrados ladrones, que pisotean las leyes del país y hacen escarnio de las garantías individuales y sociales". ${ }^{14}$ Pero todo argumento caía ante un gobierno que realizaba una obra de reconstrucción económica y rescataba a la nación del maremágnum de la lucha fratricida. Por este motivo, usaron la retórica para urdir las siguientes preguntas: “¿Contra qué estado de cosas se pretendía llevar la reacción?”, “¿contra un gobierno que salvó el país cuando se hallaba casi al borde de la ruina moral y material?”

${ }^{13}$ Copia de la carta dirigida al presidente Ubico por el licenciado Jorge García Granados, pidiendo por la vida de varios detenidos. S. f., exp. 34-6-12 (III). AHGE-SRE. Ciudad de México. Según Jorge Luján Muñoz (2000, p. 146) es posible que García Granados enviara esta misiva antes del 17 de septiembre, fecha en la cual se efectuaron los primeros fusilamientos. "Como resultado de la remisión de la carta, el abogado García Granados [nieto de un artífice de la Revolución de 1871: Miguel García Granados] fue mandado a detener ilegalmente y obligado a presenciarlos".

${ }_{14}$ “Tolerancia y reacción”, El Liberal Progresista, 13 de septiembre de 1934, p. 3. 
La única explicación ante la actitud de los conspiradores -descifrando la lógica del discurso oficial- era su mentalidad enfermiza, característica de "sujetos desprovistos de toda moralidad, carentes por completo de los más elementales escrúpulos y que, por lo mismo, han encontrado en el gobierno del general Ubico una barrera infranqueable". Por ende, para preservar la obra acometida y garantizar el bienestar social era preciso extirpar el cáncer que los acechaba. Según los funcionarios, la tolerancia se había agotado y en su lugar debía imponerse una justicia inflexible, sin distingos ni miramiento para "los traidores en toda la extensión de la palabra, una sanción ejemplar que, de una vez por todas, sirva de escarmiento a los que de tal forma quieran ensangrentar el país, y hacer befa de sus instituciones y leyes". En pocas palabras, el editorialista justificó la violencia contra los complotados, exhibiendo la racionalidad que amparó las medidas draconianas del régimen. "No se trata de una rabia sin ley-como escribió Arlette Farge (2008)-, sino de una ley que utiliza la rabia como modo de funcionamiento" (p. 45).

En total fueron doce las personas que el tribunal militar envió al paredón de fusilamiento. Días más tarde, el régimen presumió la unidad del ejército, restando importancia a la presencia de ciertos militares en el complot. Esta lealtad, según el oficialismo, reveló "la conciencia exacta de los deberes ciudadanos que alienta a todos los elementos militares $y$, a su vez, el prestigio y la simpatía que entre ellos goza el general Ubico". ${ }^{15}$ Además, en septiembre de 1934, se detonaron públicamente en el Campo Marte las bombas incautadas, acción con la cual pretendieron exaltar la reacción acertada del régimen; sin embargo, el proceso siguió abierto. Faltaba aprehender a uno de los cabecillas buscado con ahínco: Miguel García Granados, coronel que no sólo involucró a Sánchez, sino a otros que, al percatarse de su participación en este proyecto, decidieron sumarse. El régimen dirigió sus pesquisas hacia México, donde supuestamente estaba el imputado.

\section{EL PERIPLO DE DOS EXILIADOS}

Efraín Aguilar Fuentes, uno de los condenados al paredón de fusilamiento, fue interrogado en la sección de la Auditoría de Guerra de Quetzaltenango. El abogado -de 37 años de edad-proporcionó los nombres de los militares com-

15 “Actitud del elemento militar", El Liberal Progresista, 18 de septiembre de 1934, p. 3. 
plotados en la capital: Eduardo Carmona y Miguel García Granados. Manifestó, asimismo, que al conocer que este último integraba la conspiración consideró "efectiva la participación de buenos elementos y que se trataba de una cosa seria" ${ }^{16}$ La fama y el prestigio de García Granados, nieto de uno de los forjadores de la revolución de 1871, eran patentes a principios de los años treinta. Su incursión en el plano de la aviación, cuando los pájaros de acero empezaban a surcar el cielo centroamericano, le granjeó primeras planas en los periódicos.

Miguel García Granados Solís nació en Cobán, Alta Verapaz, el 14 de febrero de 1896. Veinte años más tarde entró a la Escuela Militar de Guatemala, institución donde obtuvo el grado de subteniente de infantería. Luego fue enviado a la Escuela de Señales de Fort Leavenworth, en Kansas, Estados Unidos. Su elevado rendimiento académico le valió para una estancia en la base aérea Post Field, en Oklahoma, donde fue acreditado como piloto aviador en noviembre de 1920. Diez años después fue nombrado jefe del cuerpo de la aviación militar de Guatemala, cargo que desempeñó hasta septiembre de 1933, cuando las divergencias con el ubiquismo pesaron más que su renombre y aclamadas proezas. ${ }^{17}$

García Granados objetó lo que era un secreto a voces en los pasillos del Palacio Nacional: la intención de Ubico de continuar en el poder después de 1937. Este aviador, de hecho, vivió en carne propia las consecuencias de oponerse a dicha resolución. A mediados de 1934 fue enviado al consulado de Guatemala en San Francisco, California, donde estudiaría "los últimos progresos de la aviación y las prácticas y vuelos necesarios". ${ }^{18}$ De esta forma, el oficialismo buscó derribar dos pájaros de un tíro: alejar a García Granados del

${ }^{16}$ Acta del interrogatorio efectuado a Efraín Aguilar Fuentes. 27 de septiembre de 1934. Fondo de Relaciones Exteriores, B, leg. 6722. AGCA, Guatemala.

${ }^{17}$ García Granados realizó lo que se consideró una hazaña en 1926. El coronel despegó de Guatemala piloteando un Newport y aterrizó en el aeropuerto de Ilopango, El Salvador, concretando así el primer vuelo internacional entre los países. "Mayor gloria se adjudicó -escribió Ignacio Beteta- cuando no solamente pudo llegar sin contratiempos a San Salvador, sino que pudo volver en su aparato a esta capital, con lo que contribuyó a que el pueblo de Guatemala se interesara por la aviación”. Informe del agregado militar de México en Centroamérica. S. f., exp. 45-4-49. F 72. AHGE-SRe, México.

${ }^{18}$ Comunicación del ministro de Relaciones Exteriores guatemalteco al cónsul general de Guatemala en San Francisco, California. Fondo de Relaciones Exteriores, B, leg. 6722, F.141. AGCA, Guatemala. 
tinglado político y encomendarle una misión que le daría réditos al régimen. Sin embargo, el tiro les salió por la culata.

El 26 de septiembre de 1934, mientras reconstruían los pormenores de la confabulación, el Ministerio Público ordenó la detención del coronel García Granados "por el delito de estafa y con fecha de hoy se mandó librar el suplicatorio del caso a las autoridades de México, para los efectos de su captura y consiguiente deportación" ${ }^{19}$ El militar jamás arribó al consulado. Su viaje finalizó en el puerto de Mazatlán donde, según las declaraciones de Jacobo Sánchez, desembarcó para dirigirse al Distrito Federal. Allí pretendía sumar adeptos, movilizarse a la frontera y entrar a Guatemala una vez consumada la muerte del presidente. A partir de esta fecha, el ubiquismo no cejó en conocer su paradero y concretar su extradición. Les preocupaba, sobre todo, la presencia del aviador en territorio mexicano, la experiencia y la pericia castrense que este podía compartir con los otros emigrados radicados en la vecindad.

Uno de estos sujetos, conocido por su pluma incisiva, era Clemente Marroquín Rojas. Nació en 1897 en Jutiapa, departamento del oriente guatemalteco y fronterizo con El Salvador. Desde muy joven se involucró en políti$\mathrm{ca}$, participando en las movilizaciones que pusieron punto final al prolongado gobierno de Manuel Estrada Cabrera (1898-1920). Estudió jurisprudencia en Honduras, pero pronto descubrió que esta profesión no llenaba sus expectativas vitales. Entonces optó por el periodismo, editando, junto a otros colegas, el periódico La Hora. Entusiasta, seguro de sí mismo, agresivo y belicoso -como lo describió su biógrafa Argentina Díaz Lozano (1968)-, el jalapeño usó su máquina de escribir para felicitar o denostar a los políticos de su país. Y uno de los que cayó en el segundo plano fue, precisamente, Jorge Ubico. A desnudar el ídolo se dedicó Marroquín Rojas: denunciando al candidato del Partido Progresista en 1926. El general y sus simpatizantes, perdedores de la contienda electoral, jamás olvidaron esta afrenta.

Años más tarde, cuando la grave enfermedad del presidente Lázaro Chacón (1926-1930) y el cuartelazo presidido por el general Manuel Orellana (1930) permitieron el ascenso de Ubico, Marroquín Rojas decidió abandonar Guatemala. Radicó en San Salvador, donde trabajó en una biografía de Manuel Enrique Araujo, gobernante salvadoreño asesinado en 1913. Permaneció allí hasta 1935, cuando los tentáculos del ubiquismo lo alcanzaron. Un año

${ }^{19}$ Comunicación del procurador general de la nación al ministro de Relaciones Exteriores de Guatemala. Fondo de Relaciones Exteriores, B, leg. 6722, S. F. AGCA, Guatemala. 
antes este gobierno había limado asperezas con su homólogo cuscatleco, presidido por el general Martínez, comenzando a dictar medidas en la contención de los exiliados. Una vez expulsado de El Salvador viajó hacia Honduras, donde había estudiado e incluso laborado en el Congreso. Empero, toda posibilidad de quedarse le fue denegada. Perseguido e inquieto por su precaria situación económica, se embarcó rumbo a México. Un sólo objetivo tupía su mente: conseguir el apoyo para acabar con el régimen que impedía su actividad política en Guatemala.

En septiembre de 1936, los protagonistas de este acápite dieron señales de su actividad en México. Los cuadros del ubiquismo corroboraron sus sospechas: García Granados se encontraba en la nación vecina y formaba mancuerna con Marroquín Rojas, quien, como informó la policía guatemalteca, preparaba una campaña de prensa contra Ubico. ${ }^{20}$ Bajo esta colaboración surgió a la palestra pública el Frente Revolucionario Guatemalteco. En el primer comunicado estamparon su firma, además de los sujetos citados, Eduardo Aguirre, Francisco Sartri, Rodolfo Lima y el coronel Arturo Ramírez. En este documento fustigaron a Ubico y al presidente hondureño Carías Andino (1933-1949). Además, cuestionaron al gobierno de Washington, presidido por Franklin D. Roosevelt, por su relación cercana con los regímenes centroamericanos. Finalmente, pidieron a los embajadores del continente americano evitar que los designados de Guatemala, Honduras y Nicaragua participaran en la Conferencia Interamericana de 1936.

Nosotros rogamos a su excelencia que, antes de principiar tales conferencias, luche porque sea un deber, una garantía de buena fe, que se revisen los tratados existentes para constatar la solvencia moral de cada gobierno en sus relaciones internacionales. Los gobiernos de Guatemala, Honduras y Nicaragua no deben participar en la Conferencia de Buenos Aires, porque han violado

${ }^{20}$ Producto de una conversación sostenida con el ministro de Relaciones Exteriores de Guatemala, Alfredo Skinner Klée, el encargado de negocios de la legación mexicana escribió a las autoridades: "El mismo alto funcionario me dijo que sin desconocer la amplia libertad de prensa existente en México deseaba y solicitaba, en forma amistosa, que nuestro gobierno pudiera evitar que se llevara a cabo la campaña de prensa a que se ha referido, agregando que este gobierno vería con sumo reconocimiento y agrado que tal propósito fuera logrado". Comunicación del encargado de negocios de la embajada de México en Guatemala al secretario de Gobernación de México. S. f., exp. III-13-3. AHGE-SRE, México. 
palmariamente los Tratados de Washington de 1923, que hacen imposible la reelección. ${ }^{21}$

El embajador guatemalteco acreditado en México restó importancia a la agrupación de disidentes y a sus peticiones. En una carta dirigida a Skinner Klée manifestó que el Frente Revolucionario sólo existía en la mente de sus organizadores y que no tenían más integrantes que los firmantes del comunicado. No obstante, advirtió en su misiva sobre el respaldo que estos podían conseguir de cuadros incautos, "entre los cuales se hallan algunos norteamericanos bananeros, que viven en Yucatán y Campeche, de quienes Arturo Ramírez obtiene algún dinero, haciéndoles creer en fantásticas concesiones cuando ellos triunfen" ${ }^{22}$ El temor del ubiquismo, como puede apreciarse, radicaba en el financiamiento que los exiliados podían adquirir en el extranjero. Y ciertamente el pasado reciente mostraba que no era una paranoia exacerbada.

México, debido a la tradición de asilo político territorial imperante, representó una opción idónea para los centroamericanos que huyeron de los regímenes autoritarios. Al radicarse en esta nación no sólo libraban las opciones reservadas para los disidentes: encierro, destierro o entierro, sino que dispusieron de un lugar para planificar sus acciones. Y los guatemaltecos tenían un plus: la región fronteriza para desplegar una incursión armada. "Yo no creo que debamos enfrentarnos al ejército de Guatemala -manifestó Marroquín Rojas-, creo que tendríamos éxito en una guerra irregular de pegar y correr para desquiciar al gobierno de Jorge Ubico y capitalizar hacia nuestro movimiento para asestar golpes finales" (Díaz, 1968, p. 188).

Las intenciones lucieron renovadas y las hojas volantes de los exiliados las externaban. No obstante, ¿revirtieron la determinación del gobierno mexicano de mantenerse al margen de la política exterior de sus vecinos sureños?, ¿obtuvieron el apoyo requerido?, ¿dónde lo buscaron? Estas preguntas apuntan hacia el sexenio cardenista, hacia la política exterior con la región centroamericana y las condiciones políticas reinantes en la frontera sur de México.

${ }^{21}$ Comunicado del Frente Revolucionario Guatemalteco. Fondo de Relaciones Exteriores, B, leg. 6722, s. f. AGCA, Guatemala.

${ }^{22}$ Comunicación del embajador guatemalteco en México al Ministro de Relaciones Exteriores de Guatemala. Fondo de Relaciones Exteriores, B, leg. 6722, s. f. AGCA, Guatemala. 


\section{LOS CONTACTOS DE LOS EXILIADOS Y SUS VICISITUDES}

García Granados y Marroquín Rojas pisaron suelo mexicano cuando se experimentaban fuertes tensiones y cambios. Aunque el triunfo electoral de 1934 correspondió al candidato del Partido Nacional Revolucionario, Lázaro Cárdenas demostró muy pronto que su administración no sería una prolongación del maximato. El general arribó a la presidencia empuñando banderas insignes pero rezagadas de la revolución. Ante este panorama prometió profundizar la reforma agraria, implementar la educación socialista y promover la instauración de sindicatos que velaran por el bienestar del sector obrero y campesino. Estos anuncios ayudaron a forjar el triunfo arrollador de Cárdenas en los comicios, pero su concreción suscitó resistencias a partir de 1935.

A la rebelión de Antonio Villarreal, perdedor en la elección de 1934 que se atrincheró en la frontera norte, siguió la oposición de los "camisas doradas", grupo de choque anticomunista, y la crisis política que generó la expulsión de Plutarco Elías Calles del país (Medina, 2010). Así, a mediados de 1935 era temerario vociferar un pronóstico alentador acerca del futuro de Cárdenas. "Asediado por enemigos políticos de distinto origen, [...] el nuevo presidente aparecía como un solitario, a quien sólo la voluntad y la experiencia militar de muchos años mantenían en la silla presidencial" (Sosa, 1996, pp. 51-52). Una medición de fuerzas había empezado en México y fue este escenario el que los exiliados guatemaltecos transitaron.

El caso de García Granados, el primero de nuestros desterrados que huyó del ubiquismo, adquirió matices detectivescos. La declaración de Sánchez y su rúbrica en los comunicados que se emitían desde México confirmaron su paradero. Empero, las autoridades mexicanas adujeron que había sido expulsado hacia Estados Unidos por violar las leyes migratorias. ${ }^{23}$ Ante dicha sentencia, expresó el embajador guatemalteco en México, "ya no cabía tratar sobre la extradición de dicho individuo y sólo me limité a agradecer al gobier-

${ }^{23}$ En octubre de 1934, el gobierno mexicano catalogó al aviador de "extranjero pernicioso [que] se dedica a hacer agitación obrera" y ordenaron su captura. Carta del subsecretario de la Defensa Nacional al jefe de Policía del D.F. Fondo de Gobernación. Dirección de Investigaciones Políticas y Sociales. Caja 236, exp. 24. Archivo General de la Nación (en adelante AGN), México. 
no mexicano su actitud al acceder a la expulsión de García Granados”. ${ }^{24}$ El peligro pareció disiparse. Entonces, ¿lograron tranquilizarse los ubiquistas? La falta de registros sobre su ingreso a Estados Unidos y los comunicados que continuó publicando en México mantuvieron los radares encendidos.

En septiembre de 1935, García Granados lanzó fuertes ataques contra Ubico en la revista Detective, editada en la capital mexicana. ${ }^{25}$ Meses más tarde, miembros de su familia abandonaron Guatemala por rutas solitarias hasta llegar a Tapachula, "considerando peligrosa su permanencia en este país". ${ }^{26}$ A partir de estas pruebas, el ubiquismo encargó una pesquisa a sus diplomáticos acreditados en México. Estos usaron sus contactos y algunas entrevistas para dar con el paradero del aviador. De hecho, por estas diligencias pueden rastrearse sus pasos en esta nación.

Los personeros creyeron que el imputado se hallaba ilegalmente en México. Por lo tanto, se dedicaron a comprobar diversas hipótesis. Indagaron, por ejemplo, si el aviador se desenvolvía en una instancia pública o si había obtenido la nacionalidad mexicana. El resultado fue negativo, aunque el embajador guatemalteco estableció una posibilidad: "pero hay casos en que muchos extranjeros trabajan en las oficinas públicas sin que exijan este requisito [la nacionalidad], ya sea por complacencia o porque niegan su nacionalidad". ${ }^{27}$ Tiempo después el cónsul de Tapachula le informó a su superior que García Granados administraba una finca intervenida por el gobierno y, lo más grave, que fue puesto en el cargo por Lombardo Toledano. ${ }^{28}$ El diplomático

${ }^{24}$ Comunicación del embajador de Guatemala en México al ministro de Relaciones Exteriores de Guatemala. Fondo de Relaciones Exteriores, B, leg. 6722. AGCA, Guatemala.

${ }^{25}$ Comunicación del director general de Policía de Guatemala al ministro de Relaciones Exteriores de Guatemala. Fondo de Relaciones Exteriores, B, leg. 6722. AGCA, Guatemala.

${ }^{26}$ El 27 de febrero de 1936, las autoridades mexicanas informaron sobre la internación al país de la familia del coronel, aclarando que enrumbaron hacia la capital. Comunicación del jefe del Departamento de Migración al encargado de negocios ad-interim de la embajada de México en Guatemala. S. f., exp. III-237-5. AHGE-SRE, México. En días previos fue remitido un mensaje al cónsul guatemalteco en Mariscal, Chiapas, donde le solicitaron hablar con el comandante de Ayutla, Guatemala, para practicar un riguroso registro del equipaje de la familia de García Granados, "recogiendo los documentos y cartas que puedan ser interesantes". Telegrama del ministro de Relaciones Exteriores de Guatemala al cónsul guatemalteco en Mariscal, Chiapas. Fondo de Relaciones Exteriores, B, leg. 6722, s. f. AGCA, Guatemala.

${ }^{27}$ Comunicación del embajador guatemalteco en México al ministro de Relaciones Exteriores de Guatemala. Fondo de Relaciones Exteriores, B, leg. 6722, s. f. AGCA, Guatemala.

${ }^{28}$ Todo indica que García Granados fue expulsado de México, pero aprovechó el cambio de gobierno para reingresar al país. ¿Gozaba de buenos contactos con Lázaro Cárdenas? ¿Lo apoyó Lombardo Toledano como sospechaban los ubiquistas? Difícil constatarlo por la falta 
manifestó al respecto: "no me parece imposible que uno u otro de los García Granados [incluyendo al autor de la carta a Ubico] tenga dinero para viajes, porque aquí corre como exacta la noticia de que quien sostiene a Lombardo Toledano es, aparte de otros gajes, el oro soviético".$^{29}$

La afirmación del cónsul guatemalteco contiene la interpretación del ubiquismo sobre lo que acontecía en México. Desde su visión, este país era un semillero del comunismo atestado de movimientos agraristas y sindicalistas. Ciertamente esta idea fue sostenida por Washington en los años veinte (Spenser, 2004), calando hondo en unas elites centroamericanas atrincheradas en regímenes oligárquicos. Por esta razón, prevenir cualquier contagio de estas "doctrinas exóticas" representó una urgencia cuando Lázaro Cárdenas empezó a cumplir sus promesas de campaña..$^{30} \mathrm{El}$ régimen guatemalteco, ferviente anticomunista, atisbaba huellas de su enemigo fundante por doquier y fue bajo esta lógica que temió una posible colaboración de los comunistas mexicanos con los exiliados guatemaltecos. Dinero para viajes y hasta armamento podían ser otorgados a sus enemigos, quienes adquirieron mayor peligrosidad cuando merodearon la frontera.

En efecto, las alarmas del régimen fueron activadas a principios de 1936. Sus informantes indicaron que García Granados arribaría a Tapachula para coordinar acciones con otros exiliados y militares mexicanos. Ante la noticia, el cónsul guatemalteco en Tapachula hizo la indagación correspondiente; buscó en hoteles y casas de hospedaje sin encontrar pistas del aviador. Empero, apuntó el nombre de un colaborador mexicano: el coronel Sóstenes Ruiz. Por ende, era probable que García Granados estuviera en la finca Maravilla, propiedad de los hermanos Ruiz, ubicada en Huixtla, Chiapas. Un nuevo factor se sumó entonces a los temores del régimen: la existencia de líderes locales que, irrespetando las directrices oficiales, apoyaran a los exiliados.

de fuentes, pero lo cierto fue que el 20 de diciembre de 1940, el aviador entró por nogales y obtuvo la calidad de exiliado político. Expediente de Miguel García Granados. Departamento de Migración. Guatemaltecos. Caja 4, exp. 149. AGN, México.

${ }_{29}$ Comunicación del cónsul guatemalteco en Tapachula al ministro de Relaciones Exteriores de Guatemala. Fondo de Relaciones Exteriores, B, leg. 6722, s. f. AGCA, Guatemala.

${ }^{30}$ En agosto de 1936, por citar un ejemplo, las autoridades guatemaltecas solicitaron al gobierno mexicano que sus cónsules radicados en esta nación se abstuvieran de distribuir "folletos de propaganda semi-comunista como lo han venido haciendo en Quetzaltenango y el puerto San José". Carta del secretario de Relaciones Exteriores de Guatemala enviada al embajador mexicano en Guatemala. Fondo de Relaciones Exteriores, B, leg. 6878, s. f. AGCA, Guatemala. 
Clemente Marroquín Rojas, quien colaboró en diversos periódicos de la capital mexicana, se entrevistó en más de una ocasión con cuadros del cardenismo para obtener la ayuda anhelada. Expuso un plan de incursión armada a un oficial de la Secretaría de Defensa, solicitándole rifles y municiones. Según Díaz (1968), el militar jamás respondió, y andando el tiempo el periodista se enteró que algunos de sus colegas lo habían convencido de que su proyecto "era descabellado e imposible" (p. 188). Como puede verse, las diferencias personales y de estrategia afloraron entre los desterrados. Aún así este factor no constituyó la causa de la negativa oficial. Otros aspectos deben considerarse para explicar la postura del cardenismo.

Estudiosos de la materia han indicado que la negativa de respaldar la lucha de Sandino marcó un viraje sustantivo en la política mexicana hacia Centroamérica. En adelante, el gobierno "se guardó de participar en los procesos políticos de la región y optó por explorar otras formas distintas de acercamiento" (Castillo, Toussaint y Vázquez, 2011, p. 91). El énfasis fue colocado en el comercio, la industria y la cooperación regional. Influyó en este viraje la promulgación de la doctrina Estrada, criterio de la política exterior donde se prohibió reconocer a los gobiernos de otras naciones por estimarlo una injerencia, y el objetivo del gobierno mexicano de potenciar otros mercados para la exportación de los productos nacionales. No cabe duda que este análisis nos transporta al ámbito multicausal, pero también es cierto que deja en el limbo aspectos que devienen importantes para redondear dicha explicación.

Me refiero al prurito del régimen mexicano de sostener relaciones cordiales con aquellos gobiernos que tenían la venia de la Casa Blanca. Asimismo, la reciprocidad que esperaban de sus vecinos sureños ante las revueltas que lo acechaban. En otras palabras, el cardenismo exhibió un rostro combativo con la república española, pero con los regímenes allende el Suchiate actuó de manera diferente. Para sustentar esta afirmación y examinar los aspectos señalados, al comienzo del siguiente apartado revisaré la respuesta que brindó a dos episodios: la primera reelección de Ubico y la actividad de los exiliados en su frontera sur.

\section{A BORRAR LOS RESQUEMORES PRETÉRITOS}

Pocos meses transcurrieron para que las denuncias de los complotados de 1934 resultaran ciertas. En junio de 1935 se convocó a una asamblea constitu- 
yente, anunciando con bombo y platillo la celebración de una consulta popular para sondear la reelección presidencial. El dictamen resultó previsible ante el control territorial ejercido por el régimen. Sin embargo, la iniciativa contó con una novedad que comprometió al cuerpo diplomático: le fue otorgado a los extranjeros residentes en Guatemala el derecho de participar. Desde ese momento, Fernando González Roa, embajador mexicano en funciones, comenzó a recibir consultas de sus connacionales sobre la conducta que debían observar. Otros, mientras tanto, le externaron su preocupación por una circular que habían recibido de la Sociedad Alma Azteca, en la cual se indicó la obligatoriedad de asistir a la consulta popular. González Roa, presidente honorario de dicha agrupación, desvirtuó este imperativo y elaboró unas sugerencias que envió al secretario de Relaciones Exteriores, Emilio Portes Gil.

"He podido averiguar que los extranjeros en general están dispuestos a votar -escribió el diplomático-. Me parece que la mejor manera de proceder es dejar a nuestros connacionales hacer lo que estimen conveniente. Si se les aconsejara no intervenir en el plebiscito tendríamos serias dificultades de diferentes órdenes. ${ }^{" 31}$ Según González Roa, las buenas relaciones con el gobierno vecino serían laceradas, viéndose afectados los negocios de los mexicanos residentes en Guatemala. Por otra parte, el embajador se refirió al coloso del norte y expresó: "La nación más interesada en este asunto es la Unión Americana y no conviene desde ahora tomar una situación sobre el particular." Concretada la reelección de Ubico con el aval estadunidense, sustentado en su política de buena vecindad, el cardenismo lo que menos quería era contrariar un principio que compartían. Sobre todo porque esperaban una respuesta similar hacia sus decisiones de política interna. González Roa escribió sobre los puntos favorables de esta postura:

Simplemente para citar uno diré que, si el Gobierno americano nos viera a nosotros tomar una actitud que pudiera interpretarse en el sentido de alterar en cualquier forma la política nuestra en Centro América, podría el propio Gobierno tomar una base para discurrir que hemos alterado la política de no intervención. Si el citado Gobierno norteamericano pudiera nos echaría

${ }^{31}$ Comunicación del embajador de México en Guatemala al secretario de Relaciones Exteriores de México. S. f., exp. 127-26-6. AHGE-SRE, México. Es importante anotar la experiencia que González Roa tenía en el ámbito diplomático, pues fue uno de los designados del gobierno obregonista en las conferencias de Bucareli de 1923 (Vázquez y Meyer, 2013). 
a nosotros por delante para hacer cualquier exploración o tomaría la situación contraria a nosotros en un momento dado, si creyera conveniente alterar su política en materia religiosa, por ejemplo. ${ }^{32}$

Pragmatismo y conveniencia fueron los atributos de las sugerencias del embajador, mismos que Portes Gil aprobó como líneas de acción en Guatemala. Para estos personeros, entrar en disputas con un gobierno apoyado por Washington significaba colocarse una soga al cuello cuando lo que necesitaban era libertad irrestricta para meter en cintura a sus enemigos internos. Por esta razón, el gobierno mexicano fomentó buenas relaciones con su homólogo del norte, entendimiento que desencadenó, como sostuvo Knight (1996), una respuesta "moderada, comedida y hasta a ojos de algunos críticos, complaciente" (p. 130) cuando las empresas estadunidenses vieron afectados sus intereses por la expropiación petrolera de 1938.

Este escenario internacional favoreció el anhelo de Ubico. Presumió la obtención de casi el millón de adhesiones en la consulta popular, donde sólo aparecieron 1500 votos en contra. "No hubo demostraciones ruidosas de ninguna especie -informó González Roa-, fuera de que las estaciones de radio y los magnavoces contratados dieron a conocer en la ciudad [de Guatemala] el resultado progresivo de la votación." ${ }^{33}$ Ubico preparaba sus mejores galas para asumir un segundo periodo presidencial, el cual llegaría hasta 1943. Ante este desenlace el embajador sugirió "dejar correr las cosas y observar con sumo cuidado la marcha de los acontecimientos". Los exiliados radicados en México, por el contrario, incrementaron sus protestas; se desplazaron a la frontera y tomaron acciones concretas.

En marzo de 1937, mes en el cual Ubico se colgó la banda presidencial, circuló de forma profusa un comunicado en el departamento de San Marcos, firmado por Marroquín Rojas y García Granados, entre otros. En sus párrafos manifestaron que Ubico no era más el presidente constitucional desde el 15 de marzo y, por lo tanto, era "deber de todo guatemalteco rebelarse contra su gobierno, haciendo uso de todos los medios que encuentre a su alcance". ${ }^{4}$

32 Comunicación del embajador de México en Guatemala al secretario de Relaciones Exteriores de México. S. f., exp. 127-26-6. AHGe-SRe, México.

${ }^{33}$ Comunicación del embajador de México en Guatemala al subsecretario de Relaciones Exteriores de México. S. f., exp. 127-26-6. AHGE-SRE, México.

${ }^{34}$ Comunicado de Acción Revolucionaria Guatemalteca. S. f., exp. III- 342-5. AHGE-SRE, México. 
Nuevamente el ubiquismo encendió las alarmas; envió telegramas a su homólogo mexicano, expresando que en Huixtla estaban repartiendo rifles a los exiliados guatemaltecos, al tiempo que movilizó tropas a la frontera. La simultaneidad de las acciones de los exiliados con unos disturbios acontecidos en Tacaná, municipio de San Marcos, llamó la atención de propios y extraños. ¿Habían sido los desterrados quienes los incitaron o protagonizaron?

En un periódico costarricense la respuesta fue afirmativa. Sus editores publicaron notas donde informaron acerca de la intentona revolucionaria que Marroquín concretó al frente de unos 300 hombres. "Hubo bajas de importancia por ambos lados -escribieron-. Pero Marroquín Rojas no pudo aguantar más. La entrada al territorio fue de unas 20 horas, luchando fuerte y viendo morir valientes y voluntarios." ${ }^{5}$ Según la fuente, el líder de la incursión armada designó incluso a un gabinete de gobierno, el cual no logró defender por falta de armas. Esta información fue desmentida por González Roa quien, ante el silencio sepulcral del ubiquismo, recurrió a sus contactos. El embajador mexicano negó la presencia del periodista en el Tacaná y externó en su informe que Skinner Klée aceptó que hubo problemas en la región suroccidental del país. ${ }^{36}$

Según la información recopilada por el diplomático, "un grupo de indígenas que trabajan en las fincas de café se negaron a acatar las órdenes de las autoridades, relacionadas con la distribución de braceros para la cosecha. [...] Cuando las autoridades quisieron obligarlos, estos se echaron encima de ellas y ultimaron al comandante en armas", escribió el diplomático. ${ }^{37} \mathrm{La}$ respuesta oficial fue contundente $y$, según los rumores, cobró la vida de 300 indígenas. ${ }^{38}$ La mano de hierro del régimen estuvo lista para castigar a los que infringían las reglas del sistema agroexportador. Y este mismo recurso fue el que dispusieron, como se expresó en el periódico oficial, para los exiliados que merodeaban la frontera:

35 Clemente Marroquín Rojas. La Prensa Libre, 31 de marzo de 1937, p. 3.

${ }^{36}$ Informe del embajador mexicano al secretario de Relaciones Exteriores. S. f., exp. III342-5. AHGE-SRE, México.

${ }^{37}$ En la historiografía sobre el ubiquismo se han expuesto las publicitadas giras que el gobernante efectuaba por el interior del país, urdiendo alianzas con líderes indígenas (Sabino, 2013). Sin embargo, lucen pendientes más trabajos en la línea del de Edgard Ruano (2015), quien estudió los disturbios ocurridos en Tacana como consecuencia directa de la aplicación de la Ley contra la Vagancia de 1934 y los abusos cometidos por el jefe político departamental.

${ }^{38}$ Comunicación del embajador de México en Guatemala al secretario de Relaciones Exteriores de México. S. f., exp. III-342-5. AHGE-SRE, México. 
Todo en Guatemala está en paz; el orden ha permanecido inalterable durante el tiempo que debe haber durado la pesadilla neurótica de Marroquín Rojas, como pueden testimoniarlo los viajeros que llegan diariamente con procedencia de la zona occidental, y no queda más que felicitar al autor del folletinesco relato, no por la importancia literaria del mismo, sino porque su héroe y demás fantásticos partidarios no se hayan presentado realmente del lado de acá de la frontera, porque entonces se les habría recibido en una forma digna de sus patrióticos merecimientos y ambiciones. ${ }^{39}$

A pesar de las amenazas y la fuerza militar alardeada, las peticiones del ubiquismo hacia su par mexicano plantearon la urgencia de expulsar de la frontera a los exiliados. Estos cuadros querían evitar un factor que soslayaron en sus misivas, pero evidenciaron en las disposiciones adoptadas: el reclutamiento de los trabajadores guatemaltecos que residían en la frontera sur de México. De hecho, en septiembre de 1936, cuando las acciones de los exiliados eran conocidas, prohibieron el paso de trabajadores hacia las fincas del Soconusco, aduciendo combatir el contrabando.

Si por mucho tiempo el régimen se limitó a sopesar el problema migratorio, incluyendo la precariedad de sus puestos fronterizos, en 1937 parecieron estar dispuestos a resolverlos. Así lo expresó el cónsul guatemalteco en Tuxtla Chico, Chiapas, quien tildó de ineficiente el servicio fronterizo, pues "los encargados de pasajeros en nuestra garita son tres soldados semi-analfabetas e incapaces de distinguir la condición del viajero que salva nuestra frontera" ${ }^{40}$ Por último, indicó que con estas falencias no lograrían ponerse "a cubierto contra el avance comunista sólidamente arraigado en este país [México]".

Sin embargo, la respuesta del gobierno mexicano a los pedidos del ubiquismo sosegaron esta suspicacia extrema. Primero, citaron a los exiliados y les advirtieron sobre la cancelación de su condición si persistían en sus proyectos. Después, ordenaron una inspección minuciosa en la zona fronteriza para corroborar la existencia de población armada. Al respecto, los mexicanos no sólo se conformaron con informar al ubiquismo sobre sus acciones, sino que buscaron convencerlos de su decisión de eliminar las fuentes de su mo-

39 “Tartarín de Tarascón en Guatemala”, El Liberal Progresista, 9 de abril de 1937, p. 4.

${ }^{40}$ Comunicación del cónsul guatemalteco en Tuxtla Chico, Chiapas, remitido al ministro de Relaciones Exteriores de Guatemala. Fondo de Relaciones Exteriores, B, leg. 6878, s. f. AGCA, Guatemala. 
lestia. Era claro que el cardenismo toleraba cierto activismo de los exiliados, pero quería mantenerse al margen de la política de sus vecinos. ${ }^{41}$ Marroquín Rojas encaró, entonces, la posibilidad de ser expulsado.

Antes de que esto ocurriera, el periodista y sus compañeros abandonaron Chiapas. Atrás quedaron las pláticas que habían sostenido con Gustavo Trangay y otros compatriotas residentes en Tapachula, "ansiosos de hacerle la lucha armada a Ubico" (Díaz, 1968, p. 190). Sencillamente los proyectos no cuajaron y esto respondió, como manifestó la biógrafa de Marroquín Rojas, a la presencia de cuadros de ideología marxista entre los exiliados. Estos "no pretendían realizar una revolución de carácter democrático, sino de tipo socialista, como la que en esos días presentaba el gobierno del general Lázaro Cárdenas (Díaz, 1968 p. 190). Esta afirmación, más allá de la apreciación del cardenismo, nos remite nuevamente a las discrepancias entre los exiliados, tema que aún luce pendiente en la historiografía de la región. Además, muestra las redes que los exiliados activaron en los años treinta en Chiapas. Sobre esto último cabe preguntar: ¿en realidad contaron con la cantidad de hombres y las armas que el oficialismo guatemalteco escribió en sus telegramas?

El informe elaborado por los militares mexicanos que inspeccionaron la frontera brinda una respuesta. Estos se apersonaron en la colonia ejidal Medio Monte y Sección Guillén, después recorrieron la ribera del río Suchiate: desde el puente Talismán en Tuxtla Chico hasta Unión Juárez. A lo largo del trayecto, dificultoso por lo accidentado del terreno, el batallón no encontró población armada, sino numerosos guatemaltecos que, valiéndose de argucias, obtenían trabajo de forma legal en México. Sobre este asunto informó el responsable de la expedición:

Por informes recogidos supe que existe en Tapachula una oficina que lleva como nombre "Demográfica Intersecretarial" y que según me dijeron no es

${ }^{41}$ A finales de los años cuarenta, según Moreno (2012, p. 6), el gobierno mexicano echó a andar "el crecimiento y la especialización del servicio secreto mexicano". De esta forma, durante el período cardenista el Departamento Confidencial tomó el nombre de Oficina de Información Política y Social. Luego, desde agosto de 1941 hasta 1947, dicha dependencia fue conocida como Departamento de Investigaciones Políticas y Sociales (DIPS), adscrita a la Secretaría de Gobernación. En sus informes luce el nombre de Arturo Ramírez, miembro de Acción Revolucionaria Guatemalteca, acusado de ofrecer armamento proveniente de la embajada de Alemania a los asilados nicaragüenses en 1941. Informe sobre Unión Democrática Centroamericana (UDCA). Fondo de Gobernación. Departamento de Investigaciones Políticas y Sociales. Caja 784, exp. 9. AGN, México. 
más que una "fábrica de mexicanos", es decir, que por medio de unos cuantos centavos les extienden a cualquier guatemalteco sus documentos legales para permanecer en nuestro país o una simple boleta donde dice que ya están arreglando los documentos legales y con esto se pasan todos los años, únicamente cambiándole la fecha. ${ }^{42}$

Ahora bien, ¿exageró el ubiquismo la fuerza de los exiliados o, más bien, fabricaron un enemigo con el cual justificaron el estado de emergencia perenne? La respuesta expresa los temores y la conveniencia del régimen. Un rival siempre al acecho devino útil. Su amenaza constante justificó las acciones represivas; sin embargo, la presencia de los exiliados en la frontera generó una dosis de recelo. Los temores del ubiquismo radicaban en el financiamiento de terceros y la cooptación de trabajadores guatemaltecos en las conspiraciones. De hecho, el occidente del país era propicio para fomentar revueltas y este riesgo, considerando lo sucedido en Tacaná, no estaba dispuesto a correrlo el régimen guatemalteco.

Por esta razón, valió más una sirena estridente que cualquier relajación fatal. Sobre todo porque el oficialismo sabía que los desterrados, más allá de las medidas del cardenismo, tenían el apoyo de líderes regionales. En la comunicación oficial apareció el nombre de Sóstenes y Fausto Ruiz como los principales colaboradores de los exiliados. ¿Quiénes eran estos personajes?, ¿qué papel desempeñaban en la política estatal?, ¿por qué acuerparon a los desterrados? Un examen somero de la política chiapaneca de los años treinta arrojará respuestas y algunas preguntas.

\section{ENTRE DISIDENTES}

En septiembre de 1938, el secretario de Relaciones Exteriores recibió una misiva del embajador mexicano radicado en Guatemala. El diplomático fue llamado de emergencia por las autoridades del país vecino, quienes le entregaron un memorándum donde alertaban sobre las actividades de un grupo de guatemaltecos en la región fronteriza. "El plan es invadir Huehuetenango a fines de septiembre u octubre en que los caminos estarán intransitables en

${ }^{42}$ Informe del comandante de la décimo primera zona militar, Tapachula, Chiapas, remitido al secretario de Relaciones Exteriores de México. S. f., exp. III-342-5. AHGE-SRE, México. 
Guatemala para movilizar las tropas". ${ }^{43}$ Además, citaron los nombres de quienes promovían esta acción desde México: "Parece que ahora están apoyados por los mexicanos exgeneral Fausto Ruiz, dueño de la finca Berlín del distrito Chiapa de Corzo, y su hermano Sóstenes Ruiz, domiciliado en Tapachula. Agregan esos informes que Ruiz es capitalista, opositor al gobierno de Cárdenas y que posee armamento."

Un año antes, en marzo de 1937, una comunicación similar fue emitida por el gobernador de Chiapas, Efraín Gutiérrez. Nuevamente se advirtió sobre el proyecto de una incursión armada. Entre sus protagonistas estaban Clemente Marroquín Rojas y los hermanos Ruiz en Tapachula. ${ }^{44}$ Dos aspectos resultan llamativos en la descripción elaborada sobre Sóstenes y Fausto Ruiz: su disidencia al cardenismo y la posesión de armamento. ¿Quiénes eran estos personajes y cuál fue su posición en el tablero político chiapaneco? Los hermanos Ruiz eran finqueros de la región del Soconusco involucrados en la política estatal. Durante la gubernatura del líder mapache Tiburcio Fernández Ruiz (1920-1924) elevaron una queja ante el presidente Obregón por la imposición de autoridades municipales (Spenser, 1988, p. 22) ${ }^{45}$ En medio de las rebeliones suscitadas al calor de la sucesión presidencial -delahuertista en 1923 y serranista cuatro años después-y las luchas por la gubernatura de Chiapas, Sóstenes Ruiz ejerció como comandante de la Policía Judicial y la presidencia municipal de Tapachula. ${ }^{46}$ Fausto, entretanto, ocupó la presidencia de la legislatura estatal y la secretaría general de la Confederación de Obreros y Campesinos de Chiapas. En 1932 había llegado a la gubernatura un hacendado de Chiapa de Corzo que promovió a los Ruiz en los cargos apun-

${ }^{43}$ Carta del embajador mexicano en Guatemala al secretario de Relaciones Exteriores de México. S. f., exp. III-170-19. AHge-SRE, México.

${ }^{44}$ Telegrama del gobernador de Chiapas al secretario de Gobernación. S. f., exp. III-342-5. AHge-SRe, México.

${ }^{45}$ El grupo mapache, llamado así porque sus tropas llegaban de noche a robar y comerse el maíz crudo, se hallaba liderado por finqueros fronterizos y rancheros de medios modestos (Benjamin, 1995, 147). Su lucha inició en 1914 y durante seis años combatieron a los carrancistas hasta el empate. Su destino cambió con la rebelión de Agua Prieta de 1920, cuando Fernández Ruiz se convirtió en el primer jefe del obregonismo en Chiapas.

${ }^{46}$ En enero de 1934 interpuso sus buenos oficios en la donación y labores de terracería de un espacio destinado a la construcción de viviendas para obreros. "Campo neutral", México, 3 de enero de 1934, p. 3. 
tados. ${ }^{47}$ Un coronel que, apadrinado por el jefe máximo, exhibió sin delación alguna su talante anticlerical y represivo.

Victórico Grajales era un político reconocido y respetado en Chiapas. Se rebeló contra la administración de Fernández Ruiz en 1923 y respaldó al gobierno de Obregón durante la rebelión delahuertista. Próximo a finalizar el cuatrienio de Raymundo Enríquez (1928-1932), quien apoyó su nominación, Grajales se convirtió en el primer candidato del PNR. Nunca tuvo vínculos con el movimiento obrero, y cuando ganó de forma aplastante la gubernatura, "la faz política del estado cambió radicalmente" (Benjamin, 1990, p. 264). Agradó a Calles llevando al cenit la persecución del clero y la tarea de desfanatización (Lisbona, 2008), y castigó con vehemencia toda oposición laica a su gobierno. Desde 1934 las notas en las cuales se denunciaban asesinatos y golpizas brutales fueron habituales en los periódicos chiapanecos. ${ }^{48}$ Las autoridades, mientras tanto, acusaron a los signatarios de "desorientadores sociales". ${ }^{4}$

El enfrentamiento siguió su curso e incrementó ante la sucesión de gobernador estatal de 1936. Aunque Grajales acompañó al candidato Cárdenas durante su visita a Chiapas y asistió a la toma de posesión, su mácula callista inclinó la balanza en su contra. Buscó imponer a su delfín Samuel León en las primarias del partido oficial, pero los votos favorecieron a Efraín Gutiérrez. El gobernador y algunos diputados desconocieron la victoria del jefe de campaña de Cárdenas en Chiapas. Esta expresión de rebeldía, aunado a la inestabilidad política que imperaba en el estado, propiciaron la aplicación de la desaparición de poderes en septiembre de 1936. Amador Coutiño asumió la gubernatura mientras el candidato ganador, Efraín Gutiérrez, tomaba su cargo. "De tal suerte -escribió Coutiño- que ha cesado la era de desahogos y pasiones políticas entre la familia revolucionaria chiapaneca." ${ }^{50}$ Un callista más sucumbió ante la limpieza del aparato de Estado efectuada por Cárdenas. No obstante, los hombres de Grajales continuaron metiendo en aprietos al gobierno federal en años posteriores.

${ }^{47}$ Stephen Lewis (2015, p. 139) anotó lo siguiente sobre este punto: "Grajales y su secretario oficial, el mapache reformado Fausto Ruiz, colocaron a más de 50 miembros de sus familias en el gobierno del estado en calidad de jueces, presidentes municipales y tesoreros, reporteros de periódicos y recaudadores de impuesto al alcohol".

48 "Los matoides grajalistas", Adelante, 10 de mayo de 1935, p. 2.

49 "Desorientadores sociales", Renovación, 14 de abril de 1934, p. 3.

${ }^{50}$ Telegrama del gobernador de Chiapas al presidente de México. Fondo Lázaro Cárdenas, caja 778, exp. 20, f. 86. AGN, México. 
Los hermanos Ruiz, luego del descalabro de su mentor, engrosaron las filas opositoras de la administración de Efraín Gutiérrez y, por supuesto, de Cárdenas. Su cercanía con Grajales les adjudicó una factura que inmiscuyó ataques en la prensa y la vigilancia del cardenismo. En abril de 1934, Fausto Ruiz fue vilipendiado en El Orientador Chiapaneco, periódico editado en ciudad de México, llamándolo "policastro sin escrúpulos, vergüenza y convicciones". ${ }^{51}$ Un año después el profesor de música residente en Tapachula, Mario Sánchez, solicitó el desarme de una banda de pistoleros que asolaba la región desde 1931 y estaba presidida por el teniente coronel Sóstenes Ruiz. ${ }^{52}$

Como se muestra en este documento, la tenencia de armamento por parte de los Ruiz era conocida y hasta denunciada en el Soconusco. Estos hombres, que obtuvieron su grado militar al calor de la lucha revolucionaria, representaban un peligro para algunos y excelentes aliados para otros. Esto fue captado por el cónsul guatemalteco en Tapachula, quien se apresuró a informar a su superior acerca de los movimientos de los exiliados con los hermanos Ruiz. El diplomático no sólo externó su preocupación por una eventual repartición de armas, sino que anotó la condición que estos ocupaban en el tablero político chiapaneco desde finales de 1936. Describió a los Ruiz como líderes de la zona de Tapachula y promotores de la candidatura fracasada de Samuel León, a quien acuerpó Victórico Grajales contra Efraín Gutiérrez. ${ }^{53}$ Los hermanos Ruiz, escrito en otras palabras, habían pasado del bando oficialista -callista y grajalista-a la disidencia, un estatus que compartieron con Clemente Marroquín Rojas y Miguel García Granados.

Los exiliados guatemaltecos llegaron a México cuando Cárdenas consolidaba su poder $y$, ante la negativa oficial de otorgarles armamento, aprovecharon los cismas regionales provocados por la expulsión de los callistas para promover sus planes. Los funcionarios del ubiquismo sabían que García Granados estaba escondido en la finca Maravilla, propiedad de los Ruiz. Asimismo, temieron que los fusiles que supuestamente recibía Marroquín

51 "El fariseo Fausto Ruiz en la picota”, El orientador chiapaneco, 15 de abril de 1934, p. 1; Colección Raymundo Enríquez, exp. 154. Archivo Histórico de Chiapas. Centro Universitario de Información y Documentación (en adelante AHCH-CuID), Tuxtla Gutiérrez, Chiapas, México.

${ }^{52}$ Queja del profesor Mario Sánchez. Fondo Lázaro Cárdenas. Caja 1392, exp. 84, f. 64. AGN, México.

${ }_{53}$ Carta del cónsul guatemalteco en Tapachula, Chiapas, al ministro de Relaciones Exteriores de Guatemala. Fondo de Relaciones Exteriores, B, leg. 6722, s. f. AGCA, Guatemala. 
Rojas fueran repartidos entre los trabajadores guatemaltecos apostados en la frontera sur de México. Ciertamente, los que forjaron la renuncia de Ubico no provinieron del país vecino, a diferencia de los liberales que recibieron el apoyo del presidente Benito Juárez en 1871 (Gutiérrez, 2005, p. 44). Sin embargo, las solicitudes del ubiquismo y las medidas del cardenismo para preservar la inviolabilidad de su frontera hacen que el respaldo de los Ruiz a los desterrados trascienda los meros rumores. Ahora bien, ¿por qué estos cuadros prestaron sus servicios a los exiliados?

La búsqueda infructuosa de documentos que aclaren esta cuestión me conduce a formular una suposición basada en el recelo del ubiquismo: la promesa de los desterrados de pagarle a los Ruiz o entregarles concesiones una vez que tomaran el poder. Nadie en su sano juicio se traslada a la frontera y publica comunicados si no considera reales sus posibilidades; y este fue el caso de los exiliados protagonistas de este artículo. De hecho, Miguel García Granados, bajo la bandera de la Unión Popular Guatemalteca, firmó una hoja volante que circuló en 1937. El optimismo ante una lucha entablada contra un régimen de penitenciaría y cementerio resultó evidente:

los hombres agrupados alrededor de Unión Popular Guatemalteca, ratifican su programa y sus propósitos de hace un año, y confían en que el pueblo de Guatemala, aunque en estos momentos silenciado por un tenebroso régimen político, sabrá tener el gesto de rebeldía, de virilidad y de conciencia cívica, para destruir el régimen político y social que lo agobia y escarnece. ¡Por la democracia y libertad de Guatemala! ${ }^{54}$

\section{CONCLUSIONES}

Clemente Marroquín Rojas y Miguel García Granados se retiraron de la región fronteriza cuando el gobierno mexicano amenazó con expulsarlos. El primero ejerció el periodismo en ciudad de México y continuó asestando golpes al ubiquismo por medio de sus denuncias. García Granados, entretanto, se vio envuelto en una serie de especulaciones sobre su incorporación a un contingente que partió a España para defender a la república. El oficialismo México.

${ }^{54}$ Comunicado de la Unión Popular Guatemalteca. S. f., exp. III-170-19. AHGE-SRE, 
guatemalteco nunca corroboró esta información, aunque allegados del aviador afirmaron que luchó bajo el seudónimo de Juan Gómez (Díaz, 1968, p. 188). Ya en la década de los cuarenta la colaboración estrecha entre ambos exiliados había acabado. Discrepancias ideológicas y estratégicas terminaron bifurcando sus caminos. Marroquín Rojas era ante todo un anticomunista convencido y García Granados objetó la denuncia periodística que comprometía la hospitalidad del gobierno mexicano.

El destierro fue duro y esforzado, pero terminó en julio de 1944 cuando el general Ubico presentó su renuncia. Nuestros personajes pudieron retornar por fin a su patria. García Granados se incorporó a una compañía aérea y Marroquín Rojas continuó laborando en el periódico La Hora. Años más tarde, luego del fracaso del movimiento liberacionista que derrocó a Jacobo Árbenz, el otrora disidente y potencial invasor ocupó la vicepresidencia en el gobierno de Julio C. Méndez Montenegro (1966-1970). Aquí su acendrado anticomunismo salió a relucir, pues entabló un pacto secreto con el cual se aceptó "que la institución armada dirigiera la lucha contrainsurgente sin cortapisas del gobierno civil en el marco de la aplicación de la Doctrina de Seguridad Nacional impuesta por los Estados Unidos" (Figueroa, Paz, Taracena, 2013, p. 77).

Sin duda, todavía existe mucha tela que cortar en el estudio de estas trayectorias de vida. En el presente artículo, el abordaje de un periodo de este recorrido, su exilio mexicano, ha servido para dilucidar por qué las alarmas de ambos gobiernos fueron activadas a pesar de la negativa del cardenismo de apoyar a los desterrados. De hecho, este cuestionamiento surgió cuando finalicé la lectura de las fuentes secundarias para elaborar este escrito. Llamó mi atención la movilización de tropas guatemaltecas hacia la frontera anotada por Zorrilla (1984) y las tensiones recurrentes suscitadas en la frontera sur de México. Lo anterior no encajaba con la postura que el cardenismo observó hacia su vecindad sureña: el prurito de evitar toda injerencia en sus asuntos domésticos. Por consiguiente, surgió un razonamiento que conlleva una pregunta: si México se abstuvo de intervenir en la política centroamericana durante los años treinta, ¿por qué se dieron las tensiones fronterizas reseñadas por Zorrilla?

La respuesta, por fortuna, puede encontrarse en los archivos guatemaltecos y mexicanos. En efecto, los funcionarios del cardenismo jamás atendieron las solicitudes de los exiliados. Les preocupaba la inestabilidad política que atravesaban en su territorio y esperaban que el gobierno vecino actuara de forma similar ante sus enemigos, es decir, que afianzara la inviolabilidad 
de la frontera común. A lo sumo, y esto debe subrayarse, escondieron a uno de los exiliados, Miguel García Granados, militar que el ubiquismo buscó con ahínco para expatriarlo. En otras palabras, la cordialidad imperó entre los gobiernos, pero los desterrados encontraron en los disidentes del cardenismo potenciales y decididos colaboradores. Esto fue, precisamente, lo que encendió todas las alarmas. El oficialismo guatemalteco temió una incursión armada, engrosada acaso, por los conciudadanos que laboraban en las fincas de café del Soconusco. El cardenismo, mientras tanto, ordenó a sus militares explorar la línea fronteriza para prevenir dichas acciones. Y los exiliados, aunque no cumplieron su cometido, alzaron su voz contra la política de exclusión y ausencias del ubiquismo. Tres actores que deben considerarse para examinar el tema del exilio.

\section{LISTA DE REFERENCIAS}

Balcárcel, L. (2010). El exilio guatemalteco democrático en México. En C. Véjar (coord.), El exilio latinoamericano en México (pp. 84-115). México: unAM.

Benjamin, T. (1990). El camino a leviatán: Chiapas y el Estado mexicano 1891-1947. México: Conaculta.

Benjamin, T. (1995). Chiapas: tierra rica, pueblo pobre: historia política y social. México: Grijalbo.

Castillo, M., Toussaint, M. y Vázquez, M. (2006). Espacios diversos, historia en común: México, Guatemala y Belice: la construcción de una frontera. México: SRE.

Castillo, M., Toussaint, M. y Vázquez, M. (2011). Historia de las relaciones internacionales de México, 1821-2010. Vol. 2. Centroamérica. México: SRE.

De Vos, J. (2002). La frontera sur y sus fronteras: una visión histórica. En E. Kauffer (ed.), Identidades, migraciones y género en la frontera sur de México (pp. 49-67). México: El Colegio de la Frontera Sur.

Díaz, A. (1968). Aquí viene un hombre. Biografía de Clemente Marroquín Rojas: político, periodista y escritor de Guatemala. México: Costa Amic Editor.

Farge, A. (2008). Lugares para la historia. Chile: Ediciones Universidad Diego Portales. Figueroa, C., Paz, G. y Taracena, A. (2013). El primer ciclo de insurgencia revolucionaria en Guatemala (1954-1972). En C. Aragón, C. Figueroa, A. Taracena, S. Tischler y E. Urrutia (eds.), Guatemala: historia reciente (1954-1996). T. II. La dimensión revolucionaria (pp. 29-120). Guatemala: Flacso. 
Gleijeses, P. (1989). La aldea de Jorge Ubico: Guatemala, 1931-1944. Mesoamérica, 10(17), 25-60.

Groppo, B. y Flier, P. (eds.) (2001). La imposibilidad del olvido. La Plata: Ediciones al margen.

Gutiérrez, H. (2005). En el país de la tristeza. Las misiones diplomáticas de Federico Gamboa en Guatemala. México: SRE.

Ímaz, C. (1995). La práctica del asilo y del refugio en México. México: Potrerillos editores.

Knight, A. (1996). México y Estados Unidos, 1938-1940: rumor y realidad. Secuencia, 34, 129-154. DoI: https://doi.org/10.18234/secuencia.v0i34.526

Lewis, E. (2015). Revolución ambivalente. Forjando Estado y nación en Chiapas, 1910-1945. México: UnAM.

Lida, C. (1997). Inmigración y exilio. Reflexiones sobre el caso español. México: Siglo XXI/ Colmex.

Lisbona, M. (2008). Persecución religiosa en Chiapas (1910-1940): Iglesia, Estado y feligresía en el periodo revolucionario. México: UNAM.

Medina, L. (2010). Hacia el nuevo Estado: México, 1920-2000. México: FCE.

Moreno, L. (2012). Exilio y vigilancia en México: nicaragüenses antisomocistas en la mira del servicio secreto, 1937-1947 (Tesis inédita de maestría). Instituto Mora, México.

Moreno, L. y Mejía, J. (2015). El exilio costarricense en México en la década de 1940, Cuadernos Americanos, 2, 51-73.

Ramírez, G. (2009). Sandino en Mérida. Revista de la Universidad Autónoma de Yucatán, 251-252, 3-14. Recuperado de http://www.revistauniversitaria.uady.mx/ pdf/251-2/ru251-22.pdf

Ríos, E. de los (1969). Ombres contra hombres. Guatemala: Tipografía Nacional.

Rodríguez de Ita, G. (2003). La política mexicana del asilo diplomático a la luz del caso guatemalteco: 1944-1954. México: Instituto Mora/sRE.

Ruano, E. (2015). La masacre de Tacaná. Trabajo forzado y violencia en el mundo rural bajo el régimen de Jorge Ubico. En A. Carrillo (ed.), Motines y rebeliones indígenas en Guatemala. Perspectivas historiográficas (pp. 157-201). Guatemala: Benemérita Universidad Autónoma de Puebla-Instituto de Ciencias Sociales y Humanidades "Alfonso Vélez Pliego"/Flacso-Guatemala.

Sabino, C. (2013). Tiempos de Jorge Ubico en Guatemala y el mundo. Guatemala: FCE.

Serrano, F. (2002). “... Duras las tierras ajenas...” Un asilo, tres exilios. México: FCE.

Sosa, R. (1996). Los códigos ocultos del cardenismo: un estudio de la violencia política, el cambio social y la continuidad institucional. México: UnAm/Plaza y Valdés. 
Spenser, D. (2004). El triángulo imposible. México, Rusia soviética y Estados Unidos en los años veinte. México: Centro de Investigaciones y Estudios Superiores en Antropología Social/Porrúa.

Spenser, D. (1988), El Partido Socialista Chiapaneco. Rescate y reconstrucción de su historia. México: Centro de Investigaciones y Estudios Superiores en Antropología Social. Sznajder, M. y Roniger, L. (2013), La política del destierro y el exilio en América Latina. México: FCE.

Taracena, A. (1989), El primer partido comunista de Guatemala (1922-1923). Diez años de una historia olivada. Anuario de Estudios Centroamericano, Universidad de Costa Rica, 15(1), 49-63.

Vázquez, J. y Meyer, L. (2013). México frente a Estados Unidos. Un ensayo histórico, 17762000. México: FCE.

Véliz, B. (2008). Guatemala y México: relaciones diplomáticas durante el gobierno de Jorge Ubico: una visión desde Guatemala. En P. Galeana (coord.), Historia comparada de las Américas (pp. 183-207). México: unAm/Instituto Panamericano de Geografía e Historia.

Wünderich, V. (2009). Sandino: una biografía política. Nicaragua: Universidad Centroamericana-Instituto de Historia de Nicaragua y Centroamérica.

Zorrilla, L. (1984). Relaciones de México con la República de Centro América y con Guatemala. México: Editorial Porrúa.

\section{OTRAS FUENTES}

\section{Bibliografía}

Luján, J. (2000). Dos cartas a Ubico. Anales de la Academia de Geografía e Historia de Guatemala (75), 145-168.

\section{Archivos}

AGCA Archivo General de Centro América, Guatemala.

AGN Archivo General de la Nación, México.

AHCH-CUID Archivo Histórico de Chiapas. Centro Universitario de Información y Documentación, Tuxtla Gutiérrez, Chiapas, México. 
AHgE-SRE Archivo Histórico Genaro Estrada de la Secretaría de Relaciones Exteriores de México, México.

\title{
Periódicos
}

\author{
Adelante \\ El Liberal Progresista \\ El Orientador Chiapaneco \\ El Universal \\ La Prensa Libre \\ México
}

Renovación 